\title{
Iodine Biofortification of Four Brassica Genotypes is Effective Already at Low Rates of Potassium Iodate
}

\author{
Maria Gonnella ${ }^{1}$, Massimiliano Renna ${ }^{1, *(0)}$, Massimiliano D'Imperio ${ }^{1}$, Pietro Santamaria ${ }^{2}(\mathbb{D}$ \\ and Francesco Serio ${ }^{1}$ \\ 1 Institute of Sciences of Food Production, CNR-National Research Council of Italy, Via Amendola 122/D, \\ 70126 Bari, Italy; maria.gonnella@ispa.cnr.it (M.G.); massimiliano.dimperio@ispa.cnr.it (M.D.); \\ francesco.serio@ispa.cnr.it (F.S.) \\ 2 Department of Agricultural and Environmental Science, University of Bari Aldo Moro, Via Amendola 165/A, \\ 70126 Bari, Italy; pietro.santamaria@uniba.it \\ * Correspondence: massimiliano.renna@ispa.cnr.it; Tel.: +39-080-5929306
}

Received: 23 January 2019; Accepted: 18 February 2019; Published: 21 February 2019

\begin{abstract}
The use of iodine-biofortified vegetables may be a health alternative instead of iodine-biofortified salt for preventing iodine (I) deficiency and related human disorders. In this study, four Brassica genotypes (broccoli raab, curly kale, mizuna, red mustard) were hydroponically grown with three $\mathrm{I}_{-} \mathrm{IO}_{3}{ }^{-}$rates $(0,0.75$ and $1.5 \mathrm{mg} / \mathrm{L})$ to produce iodine-biofortified vegetables. Crop performances and quality traits were analyzed; iodine content was measured on raw, boiled, and steamed vegetables. The highest I rate generally increased I content in all Brassica genotypes, without plants toxicity effects in terms of reduced growth or morphological symptoms. After 21 day-iodine biofortification, the highest I content $(49.5 \mu \mathrm{g} / 100 \mathrm{~g}$ Fresh Weight (FW)) was reached in broccoli raab shoots, while after 43 day-iodine biofortification, genotype differences were flattened and the highest I content $\left(66 \mu \mathrm{g} / 100 \mathrm{~g} \mathrm{FW}\right.$, on average) was obtained using $1.5 \mathrm{mg} \mathrm{I}-\mathrm{IO}_{3} / \mathrm{L}$. Nitrate content (ranging from 1800 to $4575 \mathrm{mg} / \mathrm{kg} \mathrm{FW}$ ) was generally higher with $0.75 \mathrm{mg} \mathrm{I}-\mathrm{IO}_{3} / \mathrm{L}$, although it depended on genotypes. Generally, boiling reduced iodine content, while steaming increased or left it unchanged, depending on genotypes. Applying low levels of I proved to be suitable, since it could contribute to the partial intake of the recommended dose of $150 \mu \mathrm{g} /$ day: A serving size of $100 \mathrm{~g}$ may supply on average $24 \%$ of the recommended dose. Cooking method should be chosen in order to preserve and/or enhance the final I amount.
\end{abstract}

Keywords: curly kale; broccoli raab; mizuna; red mustard; cooked vegetables; steaming; boiling

\section{Introduction}

Iodine (I) is an essential trace element in human nutrition, since, as component of thyroid hormones (triiodothyronine and thyroxine), its deficiency is the cause of altered functionality of the thyroid gland [1]. The Recommended Daily Allowance (RDA) value for I is $150 \mu \mathrm{g} /$ day for adults [2]. An international program of monitoring and prevention of I deficiency commenced in 1993 and aims to reach adequate level of I intake in the global population. The main action of prevention is I fortification of alimentary salt. In two decades, from 1993 to 2013, the policy of salt iodization brought about a reduction in the number of I deficient countries from 110 to 31 [2]. However, at the same time, all countries try to apply the recommendation by World Health Organization to reduce salt dietary intake to $5 \mathrm{~g}$ /day in adults. For this reason and in the cases where salt iodization is not efficient, for example in Asian countries where salt is not the main dietary condiment, alternative strategies to increase I intake in the human diet are to be implemented. Food fortification can be a good alternative [3]. Natural I sources in human diet are fish and crustaceans, then milk, eggs, meat, 
and, at last, vegetables and fruits at lower concentration, depending on the I amount in the soil [4]. In circumstances limiting or avoiding animal derived food or for groups of consumers who exclude some food categories (vegetarians and vegans, people with intolerance or allergies, people who dislikes fish/other food, inhabitants of inland regions), biofortification of some vegetables could be a good and healthy alternative source of food I and, at the same time, a challenge to face the inadequacy of vegetable intake in the Western diet [5]. Brassica vegetables are suitable to reach this goal due to the consumption of a large part of the plant (stem, leaves, and inflorescences) and their richness in natural beneficial compounds, mainly antioxidants, which together with an increased I content can confer an added value to their consumption. Moreover, Brassica are largely consumed in Asian countries, as well as in Italy, where an adequate level of I in the diet has not yet reached [6]. Hence, I biofortification in Brassica species can balance the potential inefficacy of salt iodization. Curly kale and broccoli raab are local widespread genotypes, while mizuna and red mustard are Asian genotypes recently marketed globally for baby leaf or leaf products. The first two species can be eaten only cooked (in broccoli raab, the edible portion is made of leaves, stem, and inflorescence), while the other two can be also used as raw baby leaf in salads.

Leaves are the second organ in the plant, after root, in order of accumulation of I [7]. Iodine biofortification of leafy vegetables was obtained in spinach [8,9], lettuce [10-12], and celery $[8,13]$. Among Brassicaceae, some studies of cabbage and Chinese cabbage [7], pak choi [14], and radish [15] have been carried out. In an I biofortification program, food safety is a non-negotiable point in order to avoid the risk of exceeding the I tolerable upper intake level (500-600 $\mu \mathrm{g} /$ day) in the diet [4] and, at the same time, to avoid limits to the consumption of biofortified vegetables. In this regard, two opposite examples can be reported based on the I rate and the applied biofortification protocol: On the one hand, only $25 \%$ of the RDA was obtained with $50 \mathrm{~g}$ serving of lettuce grown without soil at very low I rates $(129 \mu \mathrm{g} / \mathrm{L})$ [11]; on the other hand, more than $200 \%$ of the RDA was obtained with the same serving of spinach grown in soil at a higher I supply $(0.4 \mathrm{~g} / \mathrm{L})[16]$.

On the other hand, to our knowledge, no one has studied the effect of cooking treatment on the I content in Brassicaceae species. Cooking process is known to reduce I accumulated in leaves after biofortification [17-19]. In some studies, boiling had different effects on I content, based on the specific characteristics of the process and the vegetable matrix [17,20]. It is, therefore, advisable to assess the final content of I in a biofortified vegetable after the cooking process.

In this study, the main goal was the biofortification of Brassica leafy vegetables with low rates of I. Furthermore, since the consumption of some Brassica is predominantly cooked, the secondary goal was to assess the intake of I from biofortified Brassica after boiling and steaming were applied as cooking methods.

\section{Materials and Methods}

\subsection{Plant Material and Cultivation}

The experimental trial was carried out in a plastic (polymethacrylate) greenhouse located in Mola di Bari (at "La Noria" experimental farm of the Institute of Sciences of Food Production of the Italian National Research Council; $24 \mathrm{~m}$ above sea level; $41^{\circ} 03^{\prime} \mathrm{N}, 17^{\circ} 04^{\prime} \mathrm{E}$ ). Four genotypes belonging to the genus Brassica were compared: Brassica rapa L. (broccoli raab) (seeds from local growers), Brassica oleracea L. var. acephala (curly kale) (seeds from local growers), Brassica juncea var. japonica (mizuna) (Riccardo Larosa Sementi, Andria, BAT, Italy), and Brassica juncea (red mustard) (Riccardo Larosa Sementi, Andria, BAT, Italy).

Brassica seedlings were transplanted on 6 November 2017 at three-four true leaf stage, into pots containing $4.5 \mathrm{~L}$ of a perlite:peat mixture in a 3:1 volume ratio and received a nutrient solution (NS) containing (all element concentrations in $\mathrm{mM}$ ) nitrogen $\left(8\right.$ as $\mathrm{N}_{-} \mathrm{NO}_{3}{ }^{-}$plus 2 as $\left.\mathrm{N}-\mathrm{NH}_{4}{ }^{+}\right)$, phosphorus (1.6), potassium (5.1), magnesium (1.2), calcium (2.5), iron (0.023), copper (0.001), manganese (0.004), zinc $(0.002)$, boron $(0.025)$, and molybdenum $(0.0005)$. The experimental treatments were arranged 
according to a split-plot design with three replications, where three NSs, with different iodine levels $\left(0,0.75\right.$ and $1.5 \mathrm{mg} / \mathrm{L}$ equivalent to $0,5.9$ and $11.8 \mu \mathrm{M}$ from $\left.\mathrm{KIO}_{3}\right)$, were set in the main plots and genotypes in the sub-plots. Pots were arranged on trough-benches (with a slope of $2 \%$ ) containing 20 plants (one/pot), with each elementary unit made by ten pots. The distance between the pots was $20 \mathrm{~cm}$ within the row and $100 \mathrm{~cm}$ between rows, with a final density of five plants $/ \mathrm{m}^{2}$. Each pot was supplied with the NS through drip irrigation emitters (one/pot) set to one two-minute distribution per day. The NS was not recirculated but managed in an open cycle system. Plants were supplied with not-differentiated full strength NSs till 18 December 2017, when the two levels of I were supplied to the plants, except for the untreated controls.

Climatic parameters registered during the growing experiment are reported in Figure 1.
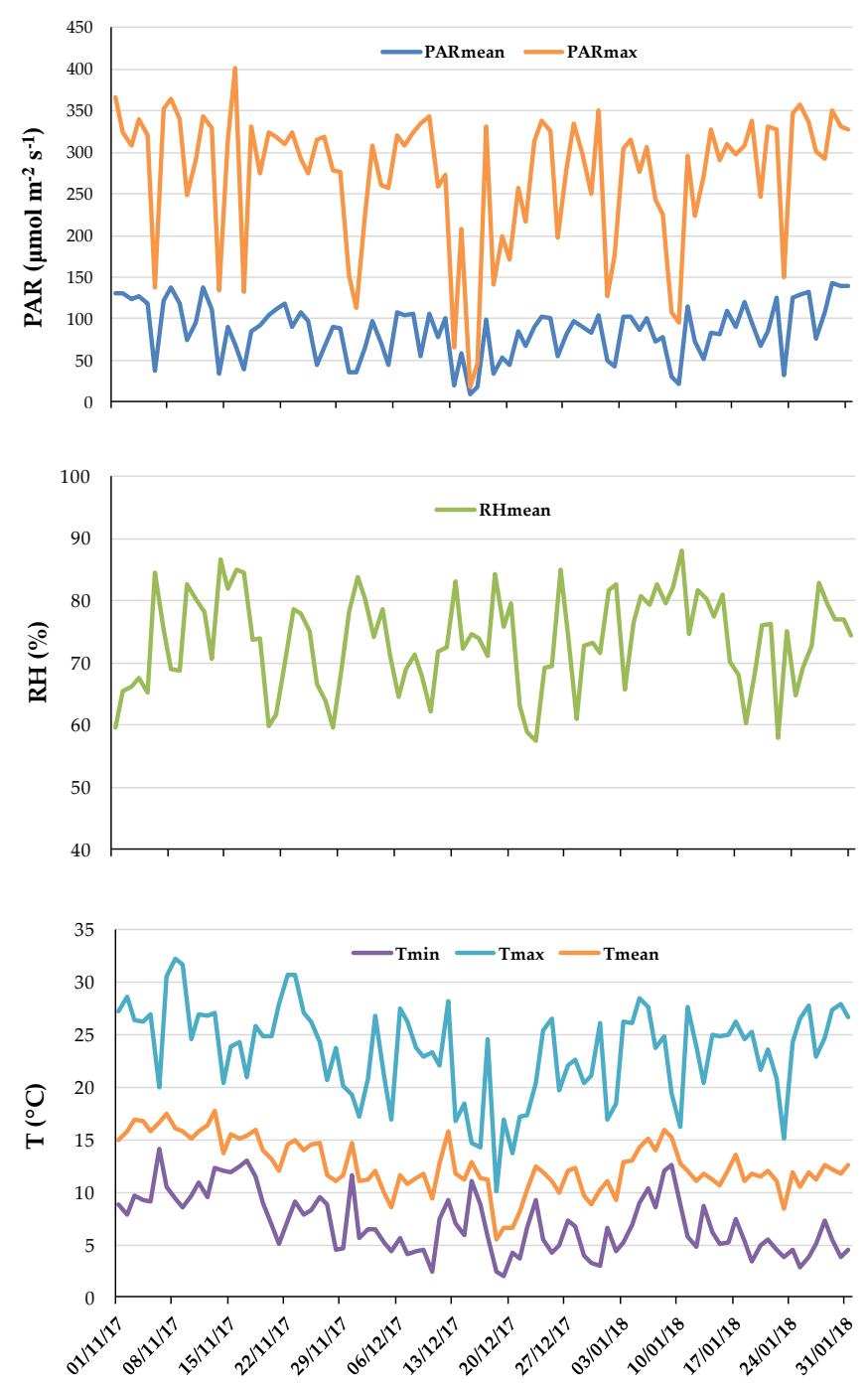

Figure 1. Photosynthetically Active Radiation (PAR), Relative Humidity (RH), average mean, minimum (min) and maximum (max) air temperatures (T), inside the greenhouse during the experiment.

\subsection{Yield and Sampling}

After 21 day-iodine treatment (8 January 2018), the first harvest was carried out, collecting five plants per unit. After measurement of fresh weight and number of leaves, three sub-samples per unit were prepared from a bulk of leaves obtained for each unit: One sub-sample for the raw product characterization (leaf color, dry matter, nitrate, and I content) and the other two for cooking processing. After 22 days more (30 January 2018), the remaining five plants per unit were sampled in order to check the I content in the raw leaves, following the same bulk method used at the first harvest. 


\subsection{Cooking Procedure}

Two sub-samples were allocated to the cooking trial, by boiling and steaming. After removing inedible parts, samples were washed with deionized water. The two cooking treatments (boiling and steaming) were applied for both the unbiofortified and biofortified vegetables. A total of 108 samples were prepared: 3 I treatments $\times 3$ post-harvest treatments (raw, boiling, and steaming) $\times 4$ genotypes $\times 3$ replicates. Cooking conditions were determined by preliminary experiments carried out according to the judgement of a group of semi-trained panelists. For all cooking treatments, the minimum time to reach tenderness for an adequate palatability and taste, according to the Italian eating habits, was referred to Reference [21]. The cooking treatments were as follows.

Boiling: Samples were boiled in a steel pot with boiling distilled water $\left(99.0 \pm 1.0^{\circ} \mathrm{C}\right)$ for $4 \mathrm{~min}$ at a vegetables/water volume ratio of 1:6. The samples were drained off and rapidly cooled on ice.

Steaming: Samples were placed on a tray in a steam cooker (VC 101630 Tefal, Milan, Italy) covered with a lid and cooked with water vapor $\left(99.0 \pm 1.0^{\circ} \mathrm{C}\right)$ for 8 min under atmospheric pressure. The samples were drained off and rapidly cooled on ice.

\subsection{Measurements and Analyses}

Color parameters were measured on raw sub-samples on 10 leaves per unit on the CIELAB scale $1976\left(\mathrm{~L}^{*}, \mathrm{a}^{*}, \mathrm{~b}^{*}\right)$ with a portable tristimulus color-meter (Minolta Chroma Meter CR-400; Minolta Camera Co. Ltd., Osaka, Japan). The instrument runs with the color-space coordinates designed as: $L^{*}$, the lightness value, ranging from black $=0$ to white $=100 ; a^{*}$, 'red/green chromaticity', red-violet color if positive, green-blue color if negative; $\mathrm{b}^{*}$, 'yellow/blue chromaticity', yellow color if positive, blue color if negative. Through trigonometric functions, other color indices were calculated: (i) Color intensity or color saturation, $\mathrm{C}^{*}=\left[\left(\mathrm{a}^{*}\right)^{2}+\left(\mathrm{b}^{*}\right)^{2}\right]^{1 / 2}$; (ii) hue angle, $\mathrm{h}^{\circ}=\tan -1\left(\mathrm{~b}^{*} / \mathrm{a}^{*}\right)$ (where $0^{\circ}=$ red-violet; $90^{\circ}=$ yellow; $180^{\circ}=$ blue-green; $270^{\circ}=$ blue) [22].

A sub-sample of the raw material was oven-dried at $105{ }^{\circ} \mathrm{C}$ until constant weight for the determination of the dry matter content. Other sub-samples used for the raw product characterization were divided in two portions: One for freeze-drying and one for oven-drying $\left(65{ }^{\circ} \mathrm{C}\right.$ until constant weight). The first was used for I determination and the second for nitrate content in raw samples. Dry material was finely ground through a mill (IKA; Labortechnik, Staufen, Germany) with a $1.0 \mathrm{~mm}$ sieve and used for quantitative $\mathrm{NO}_{3}{ }^{-}$analyses, following the method described in Reference [23] by ion chromatography (Dionex DX120, Dionex Corporation, Sunnyvale, CA, USA) with a conductivity detector, using a separation column IonPac AS14 and a pre-column IonPac AG14 (Dionex Corporation). The elution was performed using $3.5 \mathrm{mM} \mathrm{Na}_{2} \mathrm{CO}_{3}$ and $1 \mathrm{mM} \mathrm{NaHCO}_{3}$, and the flow rate was $1 \mathrm{~mL} / \mathrm{min}$ at $35^{\circ} \mathrm{C}$, current $50 \mathrm{~mA}$ (Electrolytically regenerator Suppressor: Dionex AERS $5004 \mathrm{~mm}$ RFIC). The quantification of nitrate in samples was determined by interpolation with a calibration curve, previously made with certified Element IC Standard (IC-MAN-18, CHEM-LAB).

For the inorganic I determination, we used the protocol reported in Reference [24]. Briefly, freeze-dried samples (raw and cooked) were taken and the $\mathrm{I}^{-}$was extracted with hot water $\left(60^{\circ} \mathrm{C}\right)$ and stirred for $30 \mathrm{~min}$. Then, the sample cooled down to room temperature. The product solution was well mixed and filtered through an ashless filter paper followed by a $0.2 \mu \mathrm{m}$ membrane filter. After extraction, the colorimetric reaction was performed as reported by Reference [24]. Briefly, iodate standard solution and the extracts samples $(100 \mu \mathrm{g} / \mathrm{L})$ were treated with $1 \mathrm{~mL}$ of $\mathrm{KSCN}(0.023 \% \mathrm{~m} / \mathrm{v})$, $2 \mathrm{~mL}$ of $\mathrm{NH}_{4} \mathrm{Fe}\left(\mathrm{SO}_{4}\right)_{2}(7.7 \% \mathrm{~m} / \mathrm{v})$ in $2.4 \mathrm{M} \mathrm{HNO}_{3}$ and $2 \mathrm{~mL}$ of $\mathrm{NaNO}_{2}(0.02 \% \mathrm{~m} / \mathrm{v})$. The solutions were mixed and incubated in a water bath at $60 \pm 2{ }^{\circ} \mathrm{C}$ for $1 \mathrm{~h}$ and subsequently incubated for $10 \mathrm{~min}$ in a water-ice mixture, in order to stop the colorimetric reaction. Each solution was read at $454 \mathrm{~nm}$. The standards for inorganic $\mathrm{I}^{-}$analysis were made from a $100 \mu \mathrm{g} / \mathrm{L} \mathrm{I}^{-}$stock solution, and standard concentrations ranged from 0 to $10 \mu \mathrm{g} / \mathrm{L}$. The quantification of inorganic $\mathrm{I}^{-}$in the freeze-dried samples was determined by interpolation with a calibration curve, previously made with an $R^{2}=0.9979$. The accuracy and precision of I measurement procedures were verified by testing the 
certified reference standard 1573a-Tomato Leaves powder of the National Institute for Standards and Technology (NIST).

Iodine content in peat and perlite was lower than the quantification limit (LOQ $=0.15 \mathrm{mg} / \mathrm{kg}$ of dry sample) while the rain water used to prepare the NS contained $2.51 \mu \mathrm{g} / \mathrm{L}$ of I.

Iodine content was expressed on a Fresh Weight (FW) basis, in order to give an immediate quantification of the I intake from raw and cooked Brassica genotypes.

Nutrient solution-to-shoot transfer factor (TFshoot) was calculated as follows:

$$
\text { TFshoot }=(\mathrm{IC} \text { shoot })_{\text {fresh }} / \mathrm{IC}_{\text {solution }}
$$

where $(\mathrm{ICshoot})_{\text {fresh }}$ is the shoot I concentration on FW basis and $\mathrm{IC}_{\text {solution }}$ is the corresponding solution I concentration, according to that reported by Reference [25].

\subsection{Statistical Analysis}

Statistical analysis was carried out using the GLM (General Linear Model) procedure (SAS Software, Cary, NC, USA) by a split-plot experimental design in a two-way analysis of variance (ANOVA) for parameters measured on raw samples (yield and number of leaves, color, dry matter, and nitrate and I content) and by a split-split-plot design for I content determined on cooked leaves, compared to the raw ones. The least significant difference (LSD) test $(\alpha=0.05)$ was used to establish differences between means.

\section{Results}

After 21 days of I biofortification, no toxicity effects were observed on Brassica plants regarding growth (Table 1) or morphological symptoms (Figure 2).

Table 1. Biometric parameters of Brassica genotypes supplied with different levels of I in the nutrient solution.

\begin{tabular}{lcc}
\hline \multirow{2}{*}{ Genotype } & Shoot Fresh Weight & No. of Leaves \\
\cline { 2 - 3 } & g/plant & n./plant \\
\hline Kale & $128.8 \mathrm{~d}$ & $12.1 \mathrm{c}$ \\
Broccoli raab & $327.4 \mathrm{~b}$ & $19.0 \mathrm{~b}$ \\
Mizuna & $378.4 \mathrm{a}$ & $81.8 \mathrm{a}$ \\
Red Mustard & $299.5 \mathrm{c}$ & $11.0 \mathrm{c}$ \\
\hline Iodine (mg/L) & & \\
\hline 0 & 287.0 & 30.5 \\
0.75 & 293.5 & 32.0 \\
1.5 & 270.2 & 30.4 \\
\hline Significance & & \\
\hline Genotype & $* * *$ & $\mathrm{~ns}$ \\
Iodine & $\mathrm{ns}$ & $\mathrm{ns}$ \\
Genotype $\times$ Iodine & $\mathrm{ns}$ & \\
\hline
\end{tabular}

*** Significant at $p \leq 0.001$; ns: not significant. Different letters within columns indicate significant differences at $\alpha=0.05$ by least significant difference (LSD) test.

Shoot FW, as well as number of leaves, were modified only in relation to the different genotypes, since kale produced plants with the lowest FW (66\% smaller than mizuna, which produced the biggest plants), while both kale and red mustard had the lowest number of leaves. On the other hand, broccoli raab and red mustard yielded shoot weights a bit lower than mizuna, but with a much lower number of leaves (mizuna produced a lot of thin leaves) (Table 1). Dry matter content was also not influenced by iodine biofortification. It was on average 7.1 and $9.8 \mathrm{~g} / 100 \mathrm{~g} \mathrm{FW}$, respectively, at the first and second harvest (Table 2). 


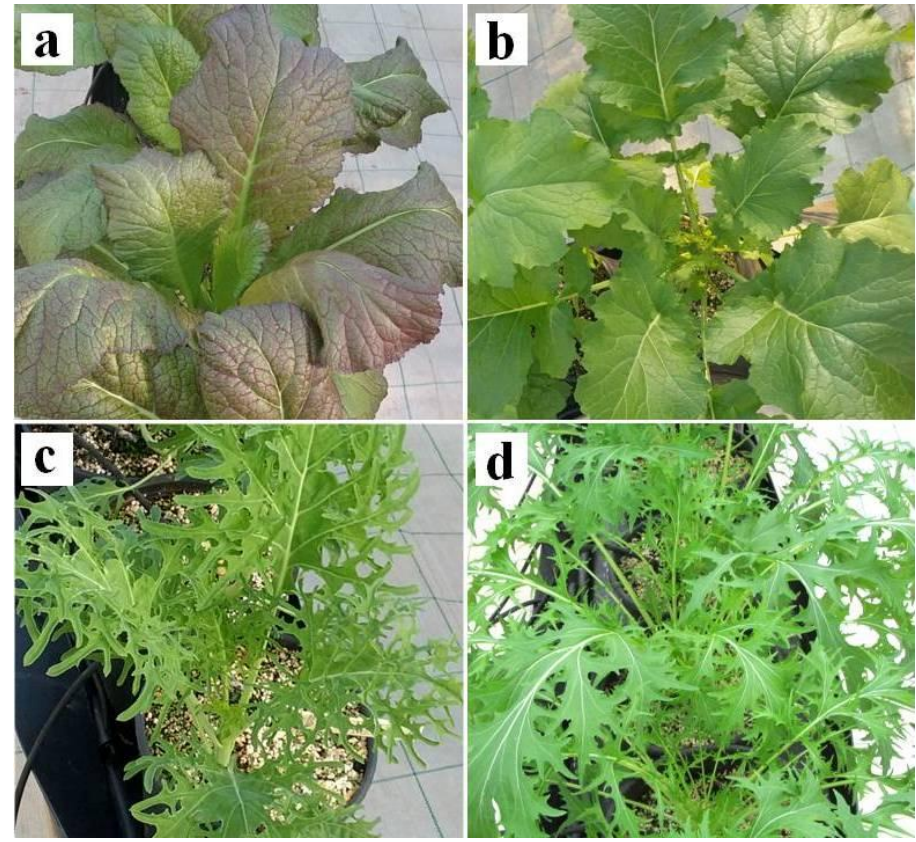

Figure 2. Plants of the four genotypes at the first harvest after 21 days of iodine biofortification. (a) red mustard; (b) broccoli raab; (c) curly kale; and (d) mizuna.

Table 2. Dry matter (DM), I concentration, and transfer factor (TF) of Brassica genotypes supplied with different levels of I in the nutrient solution (NS), measured after 21 and 43 days after iodine biofortification (I and II harvests).

\begin{tabular}{|c|c|c|c|c|c|c|c|}
\hline \multirow{3}{*}{ Genotype } & \multirow[t]{2}{*}{ NS Iodine } & \multicolumn{3}{|c|}{$\begin{array}{l}\text { I Harvest } \\
(08 / 01 / 2018)\end{array}$} & \multicolumn{3}{|c|}{$\begin{array}{c}\text { II Harvest } \\
(30 / 01 / 2018)\end{array}$} \\
\hline & & DM & Iodine & TF & DM & Iodine & TF \\
\hline & $\mathrm{mg} / \mathrm{L}$ & g/100 g FW & $\mu \mathrm{g} / 100 \mathrm{~g}$ FW & & g/100 g FW & $\mu \mathrm{g} / 100 \mathrm{~g} \mathrm{FW}$ & \\
\hline \multirow[t]{3}{*}{ Kale } & 0 & 9.40 & ND g & - & 11.27 & ND & - \\
\hline & 0.75 & 9.52 & $12.73 \mathrm{f}$ & 0.17 & 11.67 & 39.23 & 0.52 \\
\hline & 1.5 & 8.97 & 13.98 ef & 0.09 & 11.23 & 68.13 & 0.45 \\
\hline \multirow[t]{3}{*}{ Broccoli raab } & 0 & 7.16 & ND g & - & 10.40 & ND & - \\
\hline & 0.75 & 7.32 & $20.87 \mathrm{~d}$ & 0.28 & 10.20 & 34.97 & 0.47 \\
\hline & 1.5 & 7.65 & $49.47 \mathrm{a}$ & 0.33 & 9.67 & 75.70 & 0.50 \\
\hline \multirow[t]{3}{*}{ Mizuna } & 0 & 5.84 & ND g & - & 9.13 & ND & - \\
\hline & 0.75 & 5.71 & $23.64 \mathrm{~d}$ & 0.32 & 8.90 & 35.23 & 0.47 \\
\hline & 1.5 & 6.33 & $35.89 \mathrm{c}$ & 0.24 & 9.37 & 55.10 & 0.37 \\
\hline \multirow[t]{3}{*}{ Red mustard } & 0 & 5.47 & $\mathrm{ND} g$ & - & 8.63 & ND & - \\
\hline & 0.75 & 5.51 & $18.46 \mathrm{de}$ & 0.25 & 8.37 & 47.90 & 0.64 \\
\hline & 1.5 & 6.43 & $43.24 \mathrm{~b}$ & 0.29 & 9.03 & 63.70 & 0.42 \\
\hline \multicolumn{8}{|l|}{ Significance } \\
\hline Genotype & & $* * *$ & $* * *$ & $* * *$ & $* * *$ & ns & ns \\
\hline Iodine & & ns & $*$ & $* *$ & ns & * & $*$ \\
\hline Genotype $\times$ Iodine & & $\mathrm{ns}$ & $* * *$ & $* * *$ & ns & ns & ns \\
\hline
\end{tabular}

* Significant at $p \leq 0.05 ;{ }^{* *}$ Significant at $p \leq 0.01 ; * * *$ Significant at $p \leq 0.001 ;$ ns: not significant. Different letters within columns indicate significant differences at $\alpha=0.05$ by LSD test. NS: Nutrient Solution; FW: Fresh Weight; ND: Not Detected (value < quantification limit).

The lowest mean values were found in red mustard (5.8 and $8.7 \mathrm{~g} / 100 \mathrm{~g} \mathrm{FW}$ ) and mizuna ( 6.0 and $9.1 \mathrm{~g} / 100 \mathrm{~g} \mathrm{FW})$, and the highest was in kale (9.3 and $11.4 \mathrm{~g} / 100 \mathrm{~g} \mathrm{FW}$ ) at the two harvests, respectively, where red mustard and mizuna values were not statistically different from each other (Table 2; Figure 3). 

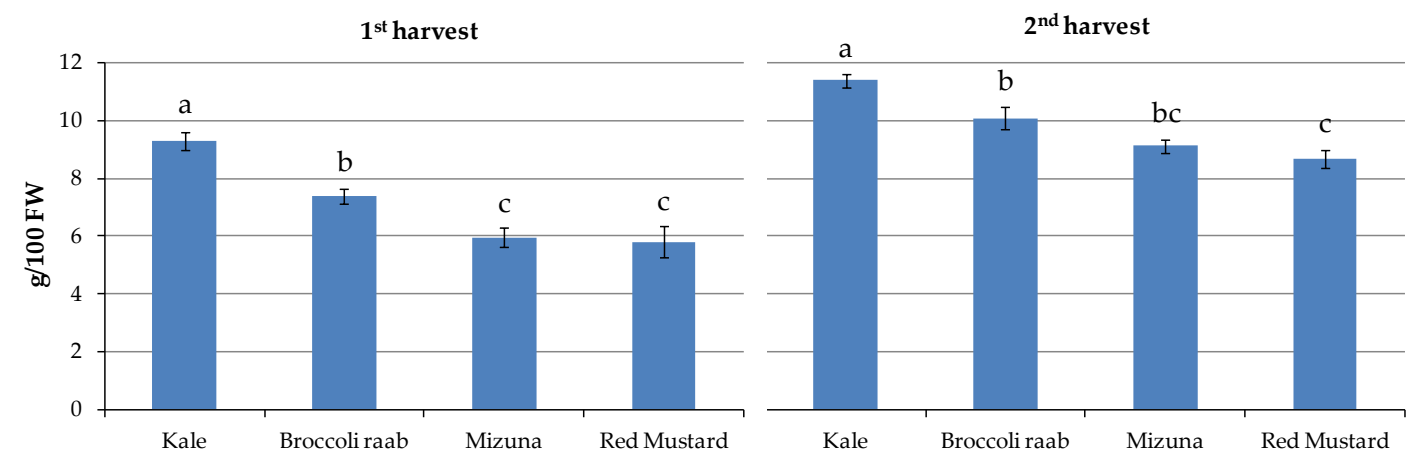

Figure 3. Effect of genotypes on DM measured at 1st and 2nd harvest ( $p \leq 0.001)$. Different letters indicate that mean values are significantly different at $\alpha=0.05$ by LSD test.

After 21 days of biofortification, I accumulation in the edible raw product reached average values of 18.9 and $35.7 \mu \mathrm{g} / 100 \mathrm{~g} \mathrm{FW}$, respectively, with 0.75 and $1.5 \mathrm{mg} / \mathrm{L}$ (Table 2). Only in kale was there no increase in I accumulation by doubling rate from 0.75 to $1.5 \mathrm{mg} / \mathrm{L}$. In the other species, I increased by 52 , 134 , and 137\%, respectively, in mizuna, broccoli raab, and red mustard (Table 2). The highest I content was found in broccoli raab at the highest level of I in the NS. At the second harvest, I content was not different between the genotypes; on the other hand, I rates had effects more pronounced, with 39.3 and $65.7 \mu \mathrm{g} / 100 \mathrm{~g} \mathrm{FW}$, respectively, corresponding to the lower and higher I concentrations in the NS (Table 2; Figure 4). As expected, taking into account the low levels of accumulated I, the calculated transfer factor from the NS to shoot $\left(\mathrm{TF}_{\text {shoot }}\right)$ was quite low in Brassica, on average 0.26 and 0.53 with $0.75 \mathrm{mg} / \mathrm{L}(5.9 \mu \mathrm{M})$, at the first and second harvest, respectively. The values were slightly lower at $1.5 \mathrm{mg} / \mathrm{L}(11.8 \mu \mathrm{M})$ (Table 2; Figure 4).
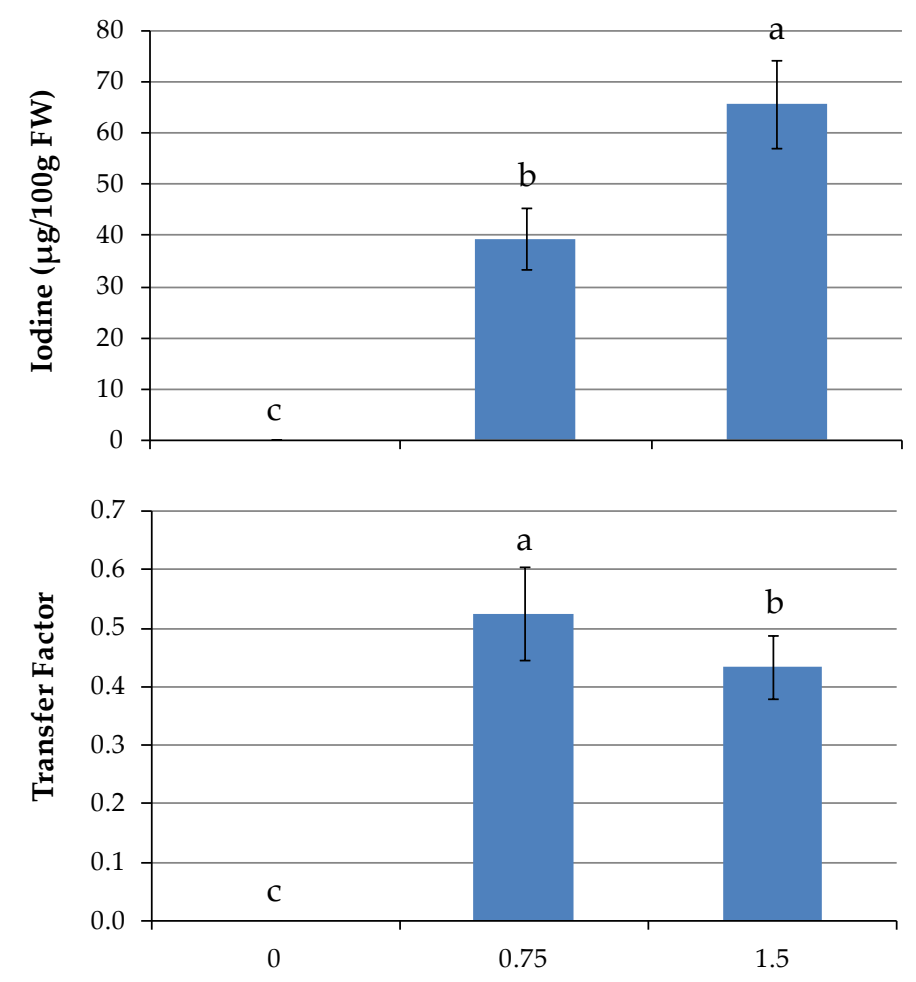

Figure 4. Effect of I rates in the nutrient solution on vegetable's I content and TF at 2nd harvest $(p \leq 0.05)$. For I level $0 \mathrm{mg} / \mathrm{L}$, values are lower than the quantification limit. Different letters indicate significant differences at $\alpha=0.05$ by LSD test.

Color parameters were influenced only by genotypes, indeed deeply different for leaf color. Main differences regarded lower $L^{*}$ for kale (darker leaves), compared to the other three genotypes 
(33.5 versus 37.1), and $a^{*}(-18.0 \%), h^{\circ}(-6.6 \%)$ and $C^{*}(-15.8 \%)$ values in red mustard lower than in green Brassica genotypes due to the reddish color of leaflet. No color parameter was modified by I biofortification (Table 3).

Table 3. Color parameters of raw leaves in Brassica genotypes supplied with different levels of I in the NS.

\begin{tabular}{lccccc}
\hline Genotype & $\mathbf{L}^{*}$ & $\mathbf{a}^{*}$ & $\mathbf{b}^{*}$ & $\mathbf{h}^{\circ}$ & $\mathbf{C}$ \\
\hline Kale & $33.53 \mathrm{~b}$ & $-14.04 \mathrm{~b}$ & 17.56 & $128.69 \mathrm{a}$ & $15.24 \mathrm{a}$ \\
Broccoli raab & $37.62 \mathrm{a}$ & $-14.36 \mathrm{~b}$ & 17.85 & $128.87 \mathrm{a}$ & $15.55 \mathrm{a}$ \\
Mizuna & $36.85 \mathrm{a}$ & $-13.18 \mathrm{~b}$ & 16.33 & $128.91 \mathrm{a}$ & $14.36 \mathrm{ab}$ \\
Red Mustard & $36.78 \mathrm{a}$ & $-11.36 \mathrm{a}$ & 19.22 & $120.33 \mathrm{~b}$ & $12.96 \mathrm{~b}$ \\
\hline Iodine & & & & & \\
\hline 0 & 35.83 & -12.94 & 17.49 & 126.28 & 14.26 \\
0.75 & 36.65 & -13.40 & 17.91 & 126.88 & 14.68 \\
1.5 & 36.10 & -13.37 & 17.83 & 126.94 & 14.65 \\
\hline Significance & & & & & \\
\hline Genotype & $* * *$ & $* *$ & $\mathrm{~ns}$ & $* * *$ & $* *$ \\
Iodine & $\mathrm{ns}$ & $\mathrm{ns}$ & $\mathrm{ns}$ & $\mathrm{ns}$ & $\mathrm{ns}$ \\
Genotype $\times$ Iodine & $\mathrm{ns}$ & $\mathrm{ns}$ & $\mathrm{ns}$ & $\mathrm{ns}$ & $\mathrm{ns}$ \\
\hline
\end{tabular}

** Significant at $p \leq 0.01 ;{ }^{* * *}$ Significant at $p \leq 0.001$; ns: not significant. Different letters within columns indicate significant differences at $\alpha=0.05$ by LSD test.

The highest $\mathrm{NO}_{3}{ }^{-}$content was found in kale leaves (mean $>4000 \mathrm{mg} / \mathrm{kg}$ FW) (Figure 5).

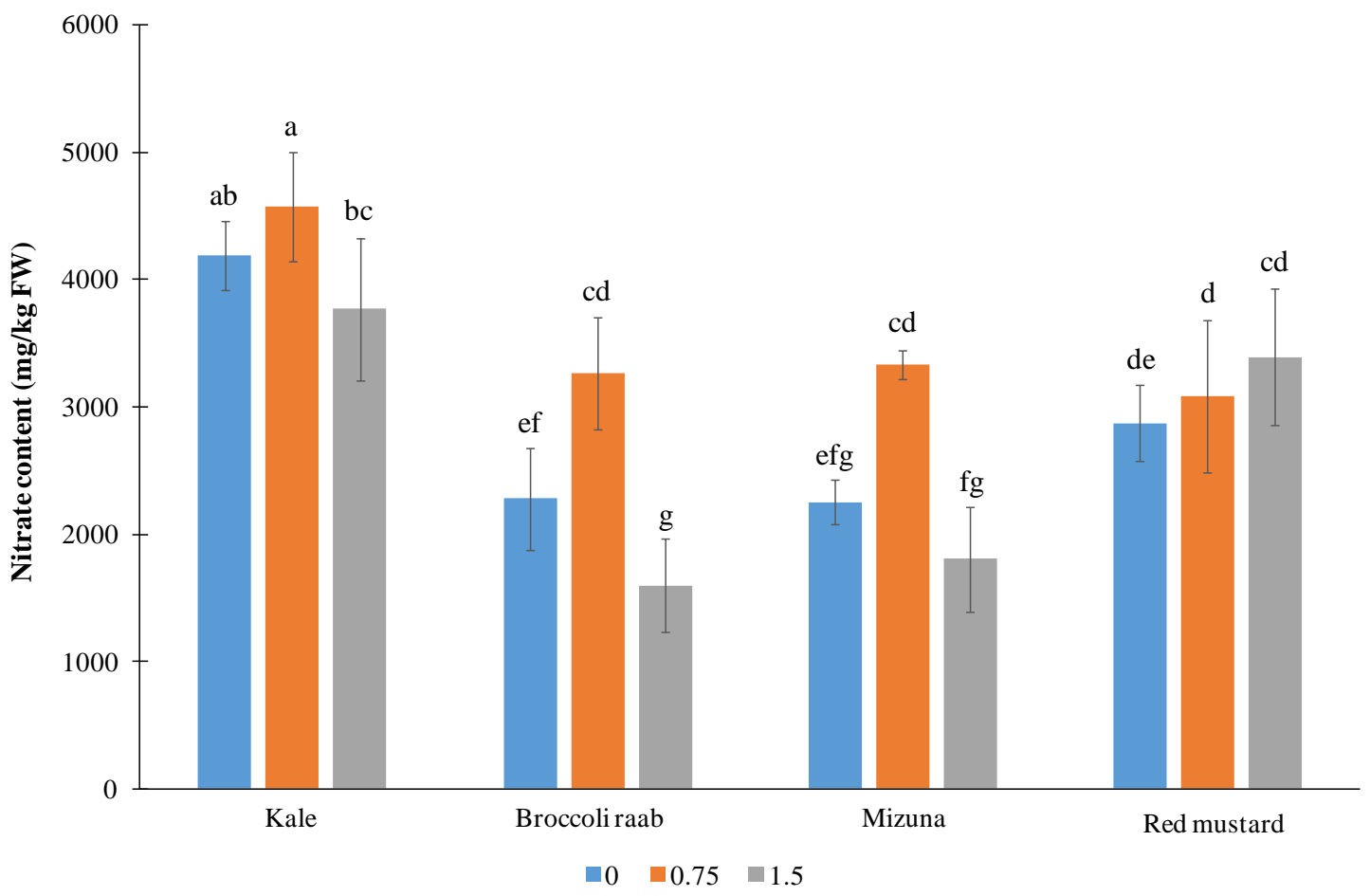

Figure 5. Nitrate content in samples of four Brassica genotypes grown with three I levels $(\mathrm{mg} / \mathrm{L})$ in the NS. Interaction significance: $p \leq 0.01$. Different letters indicate significant differences at $\alpha=0.05$ by LSD test.

The average $\mathrm{NO}_{3}{ }^{-}$content measured in the other genotypes was in the range of 2400 to $3100 \mathrm{mg} / \mathrm{kg}$ FW. Interestingly, the lowest $\mathrm{NO}_{3}{ }^{-}$content in kale, broccoli raab, and mizuna was measured with an I application of $1.5 \mathrm{mg} / \mathrm{L}$ (respectively, lower by 18,51 , and $46 \%$ than the content 
found at the intermediate I rate). The nitrate content was independent on I treatment only in red mustard, varying casually around $3000 \mathrm{mg} / \mathrm{kg}$ FW (Figure 5). In broccoli raab and mizuna, the highest accumulation was observed in plants treated with $0.75 \mathrm{mg} / \mathrm{L}$ of I (3260 and $3340 \mathrm{mg} / \mathrm{kg}$ FW, respectively), while in kale, the corresponding value was not statistically different from the untreated control.

Analytical and statistical results about the effect of the two cooking methods, genotypes, and I levels on shoot I content are given in Figure 6.

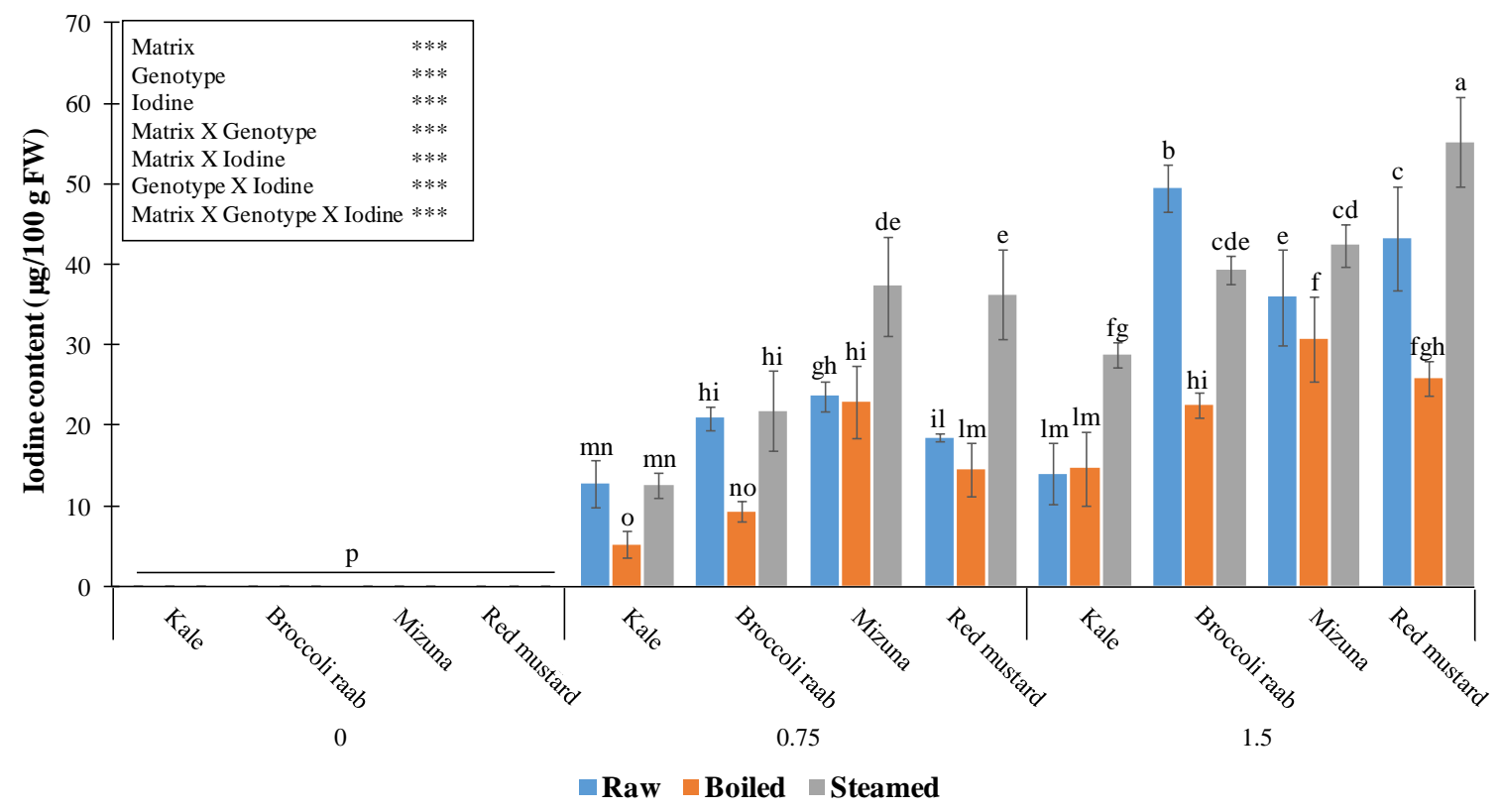

Figure 6. Iodine content in raw and cooked samples of four Brassica genotypes grown with three I levels (mg/L) in the nutrient solution. For I level $0 \mathrm{mg} / \mathrm{L}$, values are lower than the quantification limit. Different letters indicate significant differences at $\alpha=0.05$ by LSD test. In the box in the upper side of the figure, the statistical results (***: significant at $p \leq 0.001$ ) corresponding to the main factors and interactions are reported. Matrix stands for type of material (raw, boiled, and steamed).

Steaming always increased the final I amount in mizuna and red mustard, compared to the raw products, and up to doubled values in red mustard supplied with $0.75 \mathrm{mg} / \mathrm{L}$. In kale and broccoli raab, steaming did not change I content at the application of $0.75 \mathrm{mg} / \mathrm{L}$ but doubled it in kale at $1.5 \mathrm{mg} / \mathrm{L}$ (Figure 6). Only in broccoli raab supplied with $1.5 \mathrm{mg} / \mathrm{L}$ was there a $20.5 \%$ decrease of I content in the steamed, compared to the raw, product (Figure 6). Four min boiling always reduced I content, compared to the raw vegetables (in some cases more than halved), except for kale biofortified with $1.5 \mathrm{mg} / \mathrm{L} \mathrm{I}$, and mizuna and red mustard treated with $0.75 \mathrm{mg} / \mathrm{L} \mathrm{I}$ (Figure 6).

\section{Discussion}

In our experiment, I treatment had no toxicity effects on the Brassica plants after either 21 or 43 days. This was ascertained through morphological, colorimetric, and biomass production observations. Indeed, we did not expect negative effects of I biofortification on biomass production, since we chose to apply very low doses of I (5.9 and $11.8 \mu \mathrm{M})$. In comparison, other studies applied quite high levels of I, up to 39, 80, or $100 \mu \mathrm{M}$ to Chinese cabbage, lettuce, or spinach, respectively [25-27]. In Chinese cabbage, growth was depressed as early as at $0.5 \mathrm{mg} / \mathrm{L}(3.9 \mu \mathrm{M})$, and iodide was more effective than iodate in the depressing effect [26]. In lettuce iodate increased the biomass production, different than iodide [27]. Spinach biomass was not influenced by iodate, even at high doses up to $100 \mu \mathrm{M}$, while iodide was generally depressed growth [25]. The iodide form is actually more effective than iodate in biofortification processes but has a detrimental influence on plant growth, mainly due 
to its excessive accumulation in plant tissues, since it is directly taken up by plant roots [11]. On the contrary, iodate has to be reduced to iodide before its uptake [11]. These findings were at the base of our choice to use iodate as the I form for Brassica biofortification. Regarding color alterations, similar to other studies about biofortification of vegetables [28,29], our results evidenced no changes of color, notoriously considered the first quality parameter evaluated by consumers and, at the same time, the indicator of a chlorophyll status change. Similarly, chlorophyll and carotenoid contents were not changed by I fertilization (under any form) in lettuce [12], probably due to the low I concentration in treatments, while I excessive fertilization can lead to leaf chlorosis, in the older leaves more than in the young, driven by transpiration [30].

Compared to other studies, where higher I doses were applied (and recalculating I values, correspondingly), the I concentrations in Brassica leaves appeared low: $7.8 \mathrm{mg} / \mathrm{kg}$ Dry Weight (DW) was the highest value found in broccoli raab. This was a good value for our aims, but decisively low if compared to the awfully high values up to $50 \mathrm{mg} / \mathrm{kg}$ DW accumulated in lettuce when an iodate level similar to our treatments (1 mg/L) was applied in Nutrient Film Technique (NFT) [12]. If supplied with $20 \mu \mathrm{M}(2.54 \mathrm{mg} / \mathrm{L})$ of I from $\mathrm{KIO}_{3}$, lettuce leaves accumulated $566 \mathrm{mg} / \mathrm{kg} \mathrm{DW}$ [26]. Probably lettuce is a sensitive species, since its leaves also accumulated $8.1 \mathrm{mg} / \mathrm{kg}$ DW of I as maximum value [11] when exposed to very low rates of I in NS (up to $129 \mu \mathrm{g} / \mathrm{L}$ from $\mathrm{KIO}_{3}$ ). Based on our results, in Brassica genotypes, I uptake and translocation to leaves may be comparably lower. Our Brassica at $1.5 \mathrm{mg} / \mathrm{L}$ of $\mathrm{I}^{-} \mathrm{IO}_{3}$ accumulated $0.66 \mathrm{mg} / \mathrm{kg}$ FW (on average of four species) (Table 2). However, this value was only the $30^{\text {th }}$ part of what (about $20 \mathrm{mg} / \mathrm{kg}$ FW) was found in Chinese cabbage with the application of $1 \mathrm{mg} / \mathrm{L}$ of $\mathrm{I}_{-} \mathrm{IO}_{3}$ in solution culture [26]. The duration of treatments on Chinese cabbage is unclear, since the authors reported a growing cycle duration of three months when referring to a different pot experiment. Correspondingly, they observed toxicity effects and growth reduction at an iodate concentration of $0.5 \mathrm{mg} / \mathrm{L}$. These effects did not appear under our conditions-not after 21 days of treatments nor after an additional 22 days, when we did an additional sampling to check I accumulation and toxicity occurrence (Table 2). Specifically, at 43 days of biofortification, I accumulation in the edible product further increased compared to the previous harvest, with nearly doubled values. On the one hand, we could state that I accumulation was dependent on genotype aptitude, but, at the same time, it depended on the complex of the features that characterized the biofortification (applied I doses and form, supply protocol, and cultivation conditions). One aspect may be specifically crucial for I accumulation: The interference, or not, of a substrate influencing the I fate at root level [16]. Our cultivation could be ascribed to a soilless culture, where the direct mean to supply I is fertigation with an NS; however, in our experiment, plants were grown in pots containing peat in a mixture with perlite (1:3 volume ratio peat:perlite). It is known that organic matrices absorb I from the circulating solution [31]. This aspect may act in a double direction: increasing availability of I over time, covering a function of accumulation, or subtracting I from the root zone during fertigation [16]. It is sure that our plants were not in continuous contact with the NS, different than NFT or solution culture. Under these conditions, comparing our values to the $\mathrm{TF}_{\text {leaf }}$ (about 11.6) reported by Reference [25] for spinach supplied with a similar I concentration for 21 days, it is clear that the uptake and translocation efficiency of $\mathrm{I}_{-} \mathrm{IO}_{3}$ in the NS to the Brassica shoot appeared very low. Expressing these values in percentage, we can state that maximum $50 \%$ of the supplied I was taken up by Brassica plants. Nevertheless, it was noteworthy that, from the first to the second harvest, the TF of our plants was almost doubled in some cases. This could be due to an increased root volume, a higher I amount accumulated in the substrate, or simply a longer exposure to I supply.

The nitrate concentrations found in this study are reasonable values, considering that Brassica are medium nitrate accumulating species [32]. In literature, there are opposite findings about the effect of I on nitrogen uptake and nitrate accumulation in vegetables, especially regarding the I form. Iodate could limit or depress nitrification (conversion of ammonium to nitrate) and denitrification (conversion of nitrate to $\mathrm{N}_{2}$ ) in the soil. Smolen and colleagues [31] attributed the higher availability of nitrogen for carrot root uptake to this effect of iodate, compared to iodide supply, but nothing is known 
about carrot nitrate accumulation. Conversely, Signore et al. [33], applying I by leaf spraying, found that iodate biofortification had a different effect on nitrate accumulation in carrot roots depending on I rates: both low $(50 \mathrm{mg} / \mathrm{L})$ and high $(500 \mathrm{mg} / \mathrm{L})$ levels decreased nitrate content, but the first had a stronger effect. Finally, supplied by NS, iodate did not change the nitrate content in lettuce, different than biofortification with iodide. Probably, iodate induced a high absorption of nitrate but, at the same time, stimulated nitrate reductase and nitrogen assimilation (consequently nitrate did not accumulate in leaves); on the contrary, iodide decreased both the concentration of nitrate and the nitrate reductase activity [34]. Definitely, few studies have been carried out regarding the effect of I on nitrogen nutrition and nitrate accumulation to give a certain answer to this question. An additional piece of information is that iodate can be reduced to iodide by nitrate reductase, but this has been observed in extracts from phytoplankton, and not from corn seedlings [35]. It is not clear if nitrate reductase from other terrestrial plants can be effective and how iodate and nitrate interfere in this process [16]. A general hypothesis could be stated that iodate somehow influences nitrogen metabolism and nitrate accumulation, depending on the I dose, plant species, and interactions with other anions in the root environment [15].

Considering that the four Brassica genotypes are eaten as cooked vegetables, in order to assess I intake after cooking, we determined the I content in the edible product cooked by boiling and steaming. The effect of boiling was expected, as supported by some evidences in literature. For example, biofortified celery leafstalks lost $0.7 \%$ and $42.5 \%$ iodine after 2 and 30 min boiling at $100{ }^{\circ} \mathrm{C}$, respectively [13]. Other results reporting I losses after boiling regard not leafy vegetables, such as carrot, potato, or tomato $[17,20]$. Steaming losses of I are generally more contained than boiling [19], similarly to other bioactive compounds measured in Brassica vegetables [36].

Given an I concentration of $36 \mu \mathrm{g} / 100 \mathrm{~g}$ FW, found as average of the four studied Brassica genotypes, and under the hypothesis that we would eat them raw, we will cover $24 \%$ of the I RDA referred to an adult ( $150 \mu \mathrm{g} /$ day) through the consumption of only $100 \mathrm{~g}$ of fresh product. This percentage would be decreased or increased in the case of boiled or steamed product consumption, respectively. When calculated on 43 day-biofortified vegetable products, $100 \mathrm{~g}$ of Brassica would provide, on average, $66 \mu \mathrm{g} \mathrm{I}$, corresponding to $44 \%$ of RDA. Iodine biofortification of Brassica may be helpful in increasing I intake in Asian diets, which are rich in these vegetable species, and at the same time, not comprehensive of iodate fortified salt that is not used as dietary condiment. Definitely, the accumulation rate and the biofortification efficiency were very low in the studied Brassica under our conditions, compared to other studies, but this result gives an optimal margin of safety in reference to the risk of excessive dietary intake (taking into account all sources, from drinking water to iodized salt to vegetables, fish, and seafood) of I that can cause similar damage as I deficiency [37].

\section{Conclusions}

A higher I rate generally increased I content in all Brassica genotypes, without toxicity effects from the I, in terms of reduced growth or morphological symptoms, after both 21 and 43 day-I biofortification.

The maximum I content was reached in broccoli raab shoots (49.5 and $75.7 \mu \mathrm{g} / 100 \mathrm{~g} \mathrm{FW}$, respectively, in the two harvests), much lower than values found in literature for leaf vegetables. Our choice to apply low levels of I for biofortifying Brassica leafy vegetables proved to be rational since it did not damage plants and avoided the risk to overcome the recommended dose for human adult intake of $150 \mu \mathrm{g} /$ day and to occur in cases of human toxicity. At the accumulated I contents at the second harvest, a bit more than $200 \mathrm{~g}$ of raw Brassica leaves would be enough to cover the recommended dose.

The higher I rate $(1.5 \mathrm{mg} / \mathrm{L})$ did not change the nitrate content, except for broccoli raab where it was reduced. On the other hand, the lower I dose never reduced, or rather raised (broccoli raab and mizuna), the nitrate accumulation, compared to untreated plants, the effect being dependent on genotypes. 
Cooking can change I content depending on genotype but also on cooking methods. Generally, boiling reduced I content, while steaming increased it or left it unchanged. Therefore, the cooking method should be chosen in order to preserve and/or enhance the I final amount in the cooked product.

Deeper study should be made about the interference of I with nitrate, especially on nitrate reductase activity.

Author Contributions: Conceptualization, M.G. and M.R.; methodology, M.G. and M.R.; software, M.G.; validation, M.G. and P.S.; formal analysis, M.G., M.R., and M.D.; investigation, M.G. and M.R.; resources, M.G., M.R., and M.D.; data curation, M.G., M.R., and M.D.; writing—original draft preparation, M.G.; writing—review and editing, M.G., M.R., P.S., F.S., and M.D.; visualization, M.G., M.R., and P.S.; supervision, M.G., F.S., and P.S.; project administration, M.G. and F.S.; funding acquisition, F.S. and P.S.

Funding: This research was supported by the research contract between the Department of Agricultural and Environmental Science, University of Bari Aldo Moro and the Institute of Sciences of Food Production, CNR, funded by Regione Puglia Administration under the "Rural Development Programme (RDP) 2014-2020 -project "Biodiversity of vegetable crops in Puglia (BiodiverSO)," Measure 10, Sub measure 10.2, Operation 1 "Programme for the conservation and the valorization of the genetic resources in agriculture".

Acknowledgments: The authors thank Nicola Gentile for providing technical assistance during the experiment and Pasquale Del Vecchio of the Institute of Sciences of Food Production-CNR for the assistance on journals publication policy and copyright.

Conflicts of Interest: The authors declare no conflict of interest.

\section{References}

1. Zimmermann, M.B.; Boelaert, K. Iodine deficiency and thyroid disorders. Lancet Diabetes Endocrinol. 2015, 3, 286-295. [CrossRef]

2. World Health Organization. Fortification of Food - Grade Salt with Iodine for the Prevention and Control of Iodine Deficiency Disorders; World Health Organization: Geneva, Switzerland, 2014.

3. White, P.J.; Broadley, M.R. Biofortification of crops with seven mineral elements often lacking in human diets-iron, zinc, copper, calcium, magnesium, selenium and iodine. New Phytol. 2009, 182, 49-84. [CrossRef] [PubMed]

4. European Food Safety Authority (EFSA). Opinion of the Scientific Committee on Food on the tolerable upper intake level of iodine. In Tolerable Upper Intake Levels for Vitamins and Minerals; Scientific Committee on Food, Scientific Panel on Dietetic Products, Nutrition and Allergies, Eds.; EFSA: Parma, Italy, 2006; pp. 135-150.

5. Gonzali, S.; Kiferle, C.; Perata, P. Iodine biofortification of crops: Agronomic biofortification, metabolic engineering and iodine bioavailability. Curr. Opin. Biotechnol. 2017, 44, 16-26. [CrossRef] [PubMed]

6. Iodine Global Network. The Iodine Global Network: 2017 Annual Report; IGN: Seattle, WA, USA, 2018.

7. Weng, H.; Hong, C.; Xia, T.; Bao, L.; Liu, H.; Li, D. Iodine biofortification of vegetable plants-An innovative method for iodine supplementation. Chin. Sci. Bull. 2013, 58, 2066-2072. [CrossRef]

8. Dai, J.L.; Zhu, Y.G.; Zhang, M.; Huang, Y.Z. Selecting iodine-enriched vegetables and the residual effect of iodate application to soil. Biol. Trace Elem. Res. 2004, 101, 265-276. [CrossRef]

9. Smolen, S.; Sady, W. Influence of iodine form and application method on the effectiveness of iodine biofortification, nitrogen metabolism as well as the content of mineral nutrients and heavy metals in spinach plants (Spinacia oleracea L.). Sci. Hortic. 2012, 143, 176-183.

10. Blasco, B.; Rios, J.J.; Cervilla, L.M.; Sánchez-Rodrigez, E.; Ruiz, J.M.; Romero, L. Iodine biofortification and antioxidant capacity of lettuce: Potential benefits for cultivation and human health. Ann. Appl. Biol. 2008, 152, 289-299. [CrossRef]

11. Voogt, W.; Holwerda, H.T.; Khodabaks, R. Biofortification of lettuce (Lactuca sativa L.) with iodine: The effect of iodine form and concentration in the nutrient solution on growth, development and iodine uptake of lettuce grown in water culture. J. Sci. Food Agric. 2010, 90, 906-913. [PubMed]

12. Smoleń, S.; Kowalska, I.; Sady, W. Assessment of biofortification with iodine and selenium of lettuce cultivated in the NFT hydroponic system. Sci. Hortic. 2014, 166, 9-16. [CrossRef]

13. Hong, C.L.; Weng, H.X.; Yan, A.L.; Islam, E.U. The fate of exogenous iodine in pot soil cultivated with vegetables. Environ. Geochem. Health 2009, 31, 99-108. [CrossRef] 
14. Li, R.; Li, D.W.; Yan, A.L.; Hong, C.L.; Liu, H.P.; Pan, L.H.; Song, M.Y.; Dai, Z.X.; Ye, M.L.; Weng, H.X. The bioaccessibility of iodine in the biofortified vegetables throughout cooking and simulated digestion. J. Food Sci. Technol. 2018, 55, 366-375. [CrossRef] [PubMed]

15. Strzetelski, P.; Smoleń, S.; Rożek, S.; Sady, W. The effect of diverse iodine fertilization on nitrate accumulation and content of selected compounds in radish plants (Raphanus sativus L.). Acta Sci. Pol-Hortoru 2010, 9, 65-73.

16. Smoleń, S.; Ledwożyw-Smoleń, I.; Sady, W. Iodine biofortification of spinach by soil fertigation with additional application of humic and fulvic acids. N. Z. J. Crop Hortic. Sci. 2017, 45, 233-250. [CrossRef]

17. Caffagni, A.; Pecchioni, N.; Meriggi, P.; Bucci, V.; Sabatini, E.; Acciarri, N.; Ciriaci, T.; Pulcini, L.; Felicioni, N.; Beretta, M.; et al. Iodine uptake and distribution in horticultural and fruit tree species. Ital. J. Agron. 2012, 7, 32. [CrossRef]

18. Cerretani, L.; Comandini, P.; Fumanelli, D.; Scazzina, F.; Chiavaro, E. Evaluation of iodine content and stability in recipes prepared with biofortified potatoes. Int. J. Food Sci. Nutr. 2014, 65, 797-802. [CrossRef]

19. Kapusta-Duch, J.; Bieżanowska-Kopeć, R.; Smoleń, S.; Pysz, M.; Kopeć, A.; Piątkowska, E.; Rakoczy, R.; Koronowicz, A.; Skoczylas, L.; Leszczyńska, T. The effect of preliminary processing and different methods of cooking on the iodine content and selected antioxidative properties of carrot (Daucus carota L.) biofortified with (potassium) iodine. Folia Hortic. 2017, 29, 14-24. [CrossRef]

20. Comandini, P.; Cerretani, L.; Rinaldi, M.; Cichelli, A.; Chiavaro, E. Stability of iodine during cooking: Investigation on biofortified and not fortified vegetables. Int. J. Food Sci. Nutr. 2013, 64, 857-861. [CrossRef]

21. Mazzeo, T.; N’Dri, D.; Chiavaro, E.; Visconti, A.; Fogliano, V.; Pellegrini, N. Effect of two cooking procedures on phytochemical compounds, total antioxidant capacity and colour of selected frozen vegetables. Food Chem. 2011, 128, 627-633. [CrossRef]

22. McGuire, R.G. Reporting of objective colour measurement. HortScience 1992, 27, 1254-1255. [CrossRef]

23. D'Imperio, M.; Montesano, F.F.; Renna, M.; Leoni, B.; Buttaro, D.; Parente, A.; Serio, F. NaCl stress enhances silicon tissue enrichment of hydroponic "baby leaf" chicory under biofortification process. Sci. Hortic. 2018, 235, 258-263. [CrossRef]

24. Perring, L.; Basic-Dvorzak, M.; Andrey, D. Colorimetric determination of inorganic iodine in fortified culinary products. Analyst 2001, 126, 985-988. [CrossRef] [PubMed]

25. Zhu, Y.G.; Huang, Y.Z.; Hu, Y.; Liu, Y.X. Iodine uptake by spinach (Spinacia oleracea L.) plants grown in solution culture: Effects of iodine species and solution concentrations. Environ. Int. 2003, 29, 33-37. [CrossRef]

26. Weng, H.X.; Hong, C.L.; Yan, A.L.; Pan, L.H.; Qin, Y.C.; Bao, L.T.; Xie, L.L. Mechanism of iodine uptake by cabbage: Effects of iodine species and where it is stored. Biol. Trace Elem. Res. 2008, 125, 59. [CrossRef] [PubMed]

27. Blasco, B.; Rios, J.J.; Cervilla, L.M.; Sánchez-Rodríguez, E.; Rubio-Wilhelmi, M.M.; Rosales, M.A.; Romero, L.; Ruiz, J.M. Iodine application affects nitrogen-use efficiency of lettuce plants (Lactuca sativa L.). Acta Agric. Scand. B Soil Plant Sci. 2011, 61, 378-383.

28. Montesano, F.F.; D'Imperio, M.; Parente, A.; Cardinali, A.; Renna, M.; Serio, F. Green bean biofortification for Si through soilless cultivation: Plant response and Si bioaccessibility in pods. Sci. Rep. 2016, 6, 31662. [CrossRef] [PubMed]

29. D'Imperio, M.; Renna, M.; Cardinali, A.; Buttaro, D.; Santamaria, P.; Serio, F. Silicon biofortification of leafy vegetables and its bioaccessibility in the edible parts. J. Sci. Food Agric. 2016, 96, 751-756. [CrossRef] [PubMed]

30. Mackowiak, C.L.; Grossl, P.R.; Cook, K.L. Iodine toxicity in a plant-solution system with and without humic acid. Plant Soil 2005, 269, 141-150. [CrossRef]

31. Smolen, S.; Sady, W.; Rozek, S.; Ledwozyw-Smolen, I.; Strzetelski, P. Preliminary evaluation of the influence of iodine and nitrogen fertilization on the effectiveness of iodine biofortification and mineral composition of carrot storage roots. J. Elem. 2011, 16, 103-113. [CrossRef]

32. Santamaria, P. Nitrate in vegetables: Toxicity, content, intake and EC regulation. J. Sci. Food Agric. 2006, 86, 10-17. [CrossRef]

33. Signore, A.; Renna, M.; D’Imperio, M.; Serio, F.; Santamaria, P. Preliminary Evidences of Biofortification with Iodine of "Carota di Polignano", An Italian Carrot Landrace. Front. Plant Sci. 2018, 9, 170. [CrossRef] [PubMed] 
34. Blasco, B.; Rios, J.J.; Cervilla, L.M.; Sánchez-Rodríguez, E.; Rubio-Wilhelmi, M.M.; Rosales, M.A.; Ruiz, J.M.; Romero, L. Photorespiration process and nitrogen metabolism in lettuce plants (Lactuca sativa L.): Induced changes in response to iodine biofortification. J. Plant Growth Regul. 2010, 29, 477-486. [CrossRef]

35. Hung, C.C.; Wong, G.T.; Dunstan, W.M. Iodate reduction activity in nitrate reductase extracts from marine phytoplankton. Bull. Mar. Sci. 2005, 76, 61-72.

36. Volden, J.; Borge, G.I.A.; Hansen, M.; Wicklund, T.; Bengtsson, G.B. Processing (blanching, boiling, steaming) effects on the content of glucosinolates and antioxidant-related parameters in cauliflower (Brassica oleracea $\mathrm{L}$. ssp. botrytis). LWT Food Sci. Technol. 2009, 42, 63-73. [CrossRef]

37. Laurberg, P.; Cerqueira, C.; Ovesen, L.; Rasmussen, L.B.; Perrild, H.; Andersen, S.; Pedersen, I.B.; Carlé, A. Iodine intake as a determinant of thyroid disorders in populations. Best Pract. Res. Clin. Endocrinol. Metab. 2010, 24, 13-27. [CrossRef] [PubMed]

(C) 2019 by the authors. Licensee MDPI, Basel, Switzerland. This article is an open access article distributed under the terms and conditions of the Creative Commons Attribution (CC BY) license (http://creativecommons.org/licenses/by/4.0/). 